
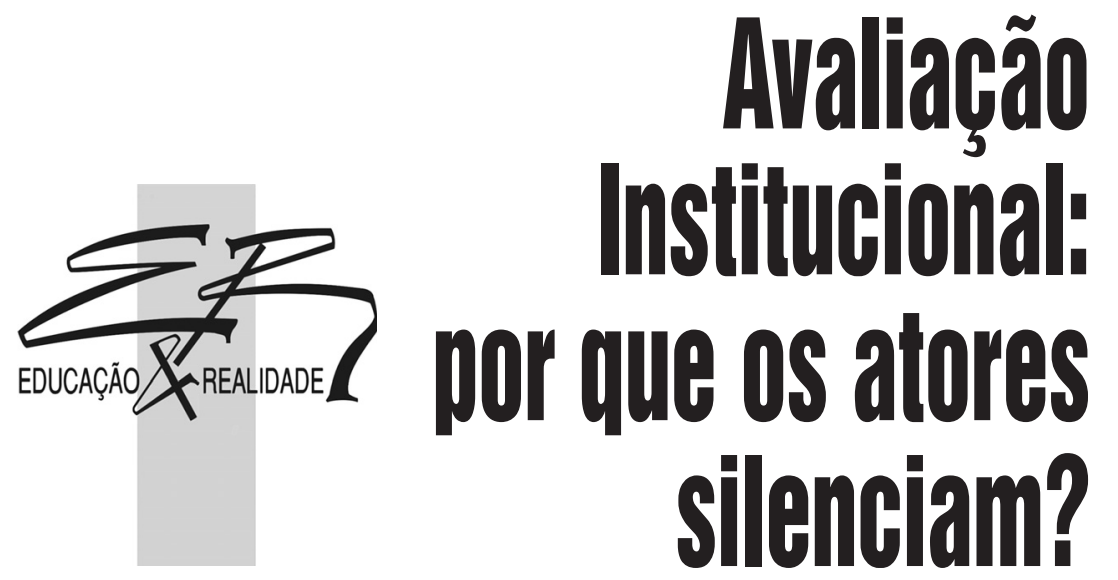

Eliane Gomes dos Santos

Maria da Glória Schwab Sadala

Sônia Xavier de Almeida Borges

RESUMO - Avaliação Institucional: por que os atores silenciam? Este artigo faz uma reflexão sobre a questão do processo de avaliação institucional nas instituições brasileiras de ensino superior, tendo como base a teoria psicanalítica e como particular enfoque, a resistência dos atores-sujeitos ao processo e à implantação da cultura de avaliação. Por meio da teoria dos discursos de Jacques Lacan foi possível refletir a respeito dos impasses da avaliação institucional no contexto universitário brasileiro e pensar em propostas frente aos fenômenos sociais a ela relacionados.

Palavras-chave: Avaliação Institucional. Psicanálise. Atores-sujeitos. Discursos.

ABSTRACT - Institutional Evaluation: why do actors silence? This article reflects on the question of the institutional evaluation process in institutions of higher education in Brazil, based on psychoanalytic theory and how a particular focus, the esistance of the actors-subjects to the process and the implementation of the evaluation culture. By the theory of Jacques Lacan's speeches could ponder the dilemmas of institutional assessment in the university context and think of Brazilian forward proposals for social phenomena associated with it.

Keywords: Institutional Evaluation. Psychoanalysis. Actors-subjects. Speeches.

Educ. Real., Porto Alegre, v. 37, n. 2, p. 551-568, maio/ago. 2012.

Disponivel em: <http://www.ufrgs.br/edu_realidade> 


\section{A Questão da Avaliação no Ensino Superior}

Historicamente, a avaliação como instrumento da Reforma Universitária (instituída pela Lei n. 5540/68, sofrendo posteriores adaptações) provocou mudanças nas áreas centrais do Ensino Superior, como financiamento, gestão institucional e autonomia universitária, explicitadas na Constituição de 1988, e estabeleceu novas bases para pensá-lo. A reforma de 1968 tornou-se um marco referencial que influenciou a concepção de qualidade dos anos seguintes.

A educação é uma das mais intensas aspirações do povo brasileiro. Nota-se em todos os grupos sociais um largo interesse e uma crescente expectativa pela melhoria da qualidade do ensino em todos os níveis. O aumento das demandas educacionais do ensino superior indicou a necessidade de sua ampliação, tendo em vista maior possibilidade de acesso, particularmente para a classe média. Desta forma ficou claro às Instituições de Ensino Superior, a necessidade de tornar mais eficientes os processos das atividades universitárias, assim como empreender maior eficácia e rendimento em suas ações. A avaliação é reconhecida como instrumento eficiente na correção de deficiências, agindo, enquanto processo, para desenvolver a excelência da qualidade do ensino.

Vários autores estudam o fenômeno avaliativo sob diversos ângulos e enfatizam a necessidade de encará-lo com seriedade e fundamentá-lo cientificamente.

A literatura apresenta diversos conceitos que apontam a avaliação institucional como meio extremamente importante na tomada de decisões. Dias Sobrinho escreve:

A avaliação é um instrumento fundamental da reforma do Estado. Nenhum Estado moderno desenvolvido pode abrir mão da avaliação. Isto significa que a avaliação é um instrumento valioso de diagnóstico interno (autoavaliação) e externo, que vem adquirindo uma importância crescente, principalmente a partir dos anos 90, que podem ser chamados de década da avaliação (Dias Sobrinho, 2003, p. 98).

Atualmente não se faz gestão universitária sem processo de avaliação, seja por imposição governamental, exigência da globalização ou porque os gestores a concebem como instrumento importante de gestão. As recentes mudanças do mundo globalizado nos direcionam para um melhor entendimento das tramas destes processos internos e dos laços sociais que perpassam pela comunidade acadêmica. Estamos em busca de novas formas de relações institucionais que são fortemente abaladas pelas mudanças que, por mais bem planejadas que sejam, esbarram em processos ligados às subjetividades dos atores envolvidos. Percebe-se uma insatisfação reinante no meio acadêmico, muitas vezes silenciosa, e uma retração na participação destes nos processos internos de avaliação. Diante desses fatos como envolver os grupos representativos da comunidade no processo de avaliação? 
Como criar uma cultura de autoavaliação e reflexão que possibilite um debate crítico?

A gestão dos projetos acadêmicos não é tarefa nada fácil devido à complexidade de sua particular estrutura ligada ao ensino, à pesquisa e à extensão.

A avaliação, como uma prática pedagógica, exige um planejamento estratégico e uma análise detalhada que traga valores importantes para o desenvolvimento da instituição, justamente para evitar que seja confundida com uma ação de controle, punitiva com respaldo nos instrumentos legais externos.

Os novos processos avaliativos do Sistema Nacional de Avaliação da Educação Superior sofrem resistências no interior das instituições decorrentes das alterações que as reformas produzem nas práticas dos atores docentes, nas diferentes culturas institucionais. A dificuldade da criação de uma cultura de avaliação, ponto falho comum identificado por teóricos e práticos do meio educacional superior ao longo dos anos, continua enigmática nos dias atuais.

Sendo a avaliação institucional um processo sem fim, mas não sem finalidade, construindo permanentemente sua realidade, não se pode concebê-la sem pensar em mudança, em dinâmica, porque a realidade social, política, organizacional, tecnológica e científica mudam de forma acelerada a cada momento, exigindo atualização e renovação constante. Belloni afirma:

Em meio a muitos retrocessos e avanços na prática, a avaliação institucional demonstra grande potencial de transformação, estando diretamente ligada à mudança e à melhoria se adequadamente instrumentalizada, uma vez que se constitui um meio, uma ferramenta e não em um fim (Belloni, 1998, p. não informada).

As reformas são vistas, por parte significativa dos docentes, como ameaça às suas práticas didático-pedagógicas. Afloram divergências quanto aos projetos e finalidades da avaliação. Todavia, um bom número de mudanças, adaptações e experiências estão sendo testadas por várias universidades. Estas estão dando tratamento especial ao setor de avaliação com profissionais capacitados que tentam manter um processo mais qualitativo.

De acordo com Cunha (2004) a tradição no Brasil aponta que o ensino estatal prevalece e que é centralmente controlado. Essa característica de Estado controlador, segundo o autor, permeou o ensino superior brasileiro desde o Império até o início do século XX.

Que função tem o controle e quais os resultados que se obtêm com este modelo centralizador? É importante esclarecer que historicamente a avaliação das instituições segue duas linhas: a da emancipação e a da regulação. A primeira, que tem a sua origem em algumas universidades na década de 1980, pressupõe o ato autônomo da universidade em prestar contas à sociedade, e que a avaliação é, por outro lado, uma das ferramentas de gerenciamento e de tomada de decisões das instituições de ensino. Contudo, a segunda tem como base a ideia neoliberal de que o papel do estado em relação à educação consiste em avaliar as instituições de ensino. 
A diferença básica entre as duas linhas é a instância onde ocorre a significação do que é qualidade. Na visão neoliberal, os técnicos das agências estatais é que definem o que é qualidade bem como os indicadores a serem utilizados para aferi-la. Para Tomaz Tadeu da Silva (2007) é complexa a tarefa de analisar a atual situação educacional feita pelo discurso neoliberal. Isto porque fica realmente muito difícil discordar de um discurso que anuncia uma qualidade total. O que dizer ou fazer mediante tal afirmação?

Esse discurso elimina outras formas de pensar e discutir a sociedade e a educação. Segundo Tomaz Tadeu da Silva "Ele tende a suprimir as categorias com as quais tendíamos a pensar a vida social e a educação, ajudando-nos a formular um futuro e uma possibilidade que transcendessem a presente e indesejável situação social" (2007, p. 21). E acrescenta:

O discurso da qualidade total, das excelências da livre iniciativa, da "modernização", dos males da administração pública reprime e desloca o discurso da igualdade/desigualdade, da justiça/injustiça, da participação política numa esfera pública de discussão e decisão, tornando quase impossível pensar numa sociedade e numa comunidade que transcendam os imperativos do mercado e do capital (Silva, 2007, p. 21- 22).

Na avaliação participativa e emancipatória a definição da qualidade e dos indicadores é negociada com os agentes do processo (professores, administrativos, alunos).

Boclin, educador dedicado ao tema de avaliação, propõe um modelo de autoavaliação por meio de indicadores de desempenho (Boclin, 2006). Afirma que "[...] utilizar indicadores de modo eficiente supõe a adoção de um modelo específico de promover uma administração eficaz" (2006, p. 43). Na visão de Boclin, esse modelo formado por indicadores de desempenho, aproxima-se do ideal, principalmente, para efeitos de uma gestão de qualidade, tão primordial nos dias atuais:

O modelo de avaliação institucional baseado em informações mensuráveis de natureza qualitativa e quantitativa, minimizando conclusões subjetivas, sendo contínuo na medida da construção de uma política institucional interna de avaliação (Boclin, 2006, p. 24).

Philippe Perrenoud transmitiu suas experiências sobre avaliação buscando caminhos para minimizar as diferenças no contexto complexo da aplicação da avaliação e da implantação da cultura nas instituições de ensino. Perrenoud, em seu livro Avaliação: da excelência à regulação das aprendizagens: entre duas lógicas, mostra a complexidade do problema da avaliação:

[...] à diversidade das lógicas em questão, a seus antagonismos, ao fato de que a avaliação está no âmago das contradições do sistema educativo e, constantemente, na articulação da seleção e da formação, do reconhecimento e da negação das desigualdades (Perrenoud, 1999, p. 10). 
O poder que a instituição detém limita o processo de autoavaliação ao sistema de controle porque a tendência é ampliar, reproduzir e aprofundar o papel do Estado, ou da burocracia universitária. Mas para além do controle, enquanto processo, é fundamental que haja uma cultura de avaliação. É necessário que cada ator-sujeito, professores, coordenadores, alunos, gestores e funcionários, tenha sua importância no processo e seja engajado no sistema avaliativo.

\section{Por uma Avaliação mais Qualitativa: um giro pelos discursos}

As universidades têm a particularidade de serem instituições que atuam em interação com a sociedade localizada em seu entorno. Com um modelo próprio de gestão, a Universidade é reflexo do Estado e da Sociedade em que se situa.

A Lei das Diretrizes e Bases da Educação Nacional - LDB, Lei no . 9.394, em seu Artigo 52 comenta: "As universidades são instituições pluridisciplinares de formação dos quadros profissionais de nível superior, de pesquisa, de extensão e de domínio e cultivo do saber humano" (Brasil, 1996, online).

A UNESCO, conforme o documento elaborado para a Conferência Mundial sobre o Ensino Superior no Século XXI: visão e ação, define assim as instituições de ensino superior dentre as quais o estabelecimento universitário:

[...] são sistemas complexos que interagem com as instituições de seu ambiente, isto é, com os sistemas políticos, econômicos, culturais e sociais. São influenciadas pelo ambiente local e nacional (ou meso-ambiente) e, cada vez mais, pelo ambiente regional e internacional (macro-ambiente). Mas por sua vez, podem e mesmo devem influenciar esses diversos tipos de ambientes (UNESCO, 1998, p. 105).

A inserção das instituições na política nacional de avaliação interfere na direção das práticas avaliativas, diz respeito à forma de relação estabelecida pela instituição com os setores oficiais responsáveis pela política de avaliação oficial, assim como com o conjunto das instituições de ensino superior.

Todas as ações na universidade são realizadas em favor do conhecimento e da racionalidade científica, e o resultado mais significativo disso é a exclusão, nesta cena, do sujeito como sujeito do desejo. Essa atitude adotada pela universidade, na visão do psicanalista Jacques Lacan, é característica de sua adoção do discurso da ciência, a serviço do capitalismo, com consequências, não só para o ensino, como também para o processo de avaliação.

O desafio da avaliação é o de exercer um papel estratégico de modo a incluirmos os atores como sujeitos no processo, que é o mesmo que dizer possibilitar o giro pelos discursos. Só assim, tomando de Bourdieu as palavras pode-se ter pesquisa viva. Os atores terão saído das margens para o centro do processo (Bourdieu, 2003, p. 71-72). 
O que uma avaliação institucional pode operar é a mudança da cultura. Mas toda essa discussão leva-nos a voltar à consideração de que para alguns autores, nos últimos dez anos, a avaliação institucional no Brasil, tende a assumir um caráter controlador e regulador, regido, portanto, pelos discursos que causam esse efeito.

No meio de toda essa mudança de conceitos, conclui-se pelas considerações acima apresentadas que não só os alunos, mas os professores universitários, atualmente no Brasil, estão submetidos paulatinamente à lógica de mercado, estimulados pelos modelos externos de avaliação, de modo a serem fortemente atingidos na sua condição de poder e autoridade, ficando como diz Bourdieu "à margem" (Bourdieu, 2003, p. 71-72), perdendo, por isto mesmo, sua crença nas possibilidades mais transformadoras da avaliação. Bourdieu, ao aprofundar suas pesquisas sobre a posição do professor nas práticas institucionais docentes, concluiu:

[...] Infelizmente, o que se chama ensino, de modo corrente, são lugares de transmissão, codificada, rotinizada do saber, e uma parte considerável da inércia dos campos científicos vincula-se ao atraso estrutural resultante do fato de que as pessoas que ensinam são comumente desconectadas da atividade de pesquisa. Assim, bizarramente, não é exagerado dizer que o ensino é, em parte, um fator de inércia. Os professores têm interesses inconscientes pela inércia. Uma vez que não estão conectados diretamente à pesquisa viva, são solidários da rotina, pelo simples fato de estarem estatutariamente, um pouquinho à margem, e eles têm, mesmo, às vezes, um interesse inconsciente em desqualificar o que é eminente. [...] Assim como, segundo Weber, o padre rotiniza a mensagem do profeta, o professor rotiniza, banaliza o discurso criador, em particular, fazendo desaparecer o que é fundamental, isto é: O problema tal como colocou o criador (Bourdieu, 2003, p. 71-72, grifo nosso).

A avaliação institucional, no seu sentido mais amplo, é a junção das duas dimensões da realidade: a das estruturas de poder e seus dirigentes e a dos atores-sujeitos, responsáveis, em última instância, pelo funcionamento de todo o sistema. "Toda avaliação opera com valores, nenhuma é desinteressada e livre das referências valorativas dos distintos grupos sociais", defende Dias Sobrinho (2003, p. 113).

A realidade é que algumas IES fazem sua autoavaliação para cumprir as determinações do MEC. O Instituto de Pesquisas em Educação - IPAE atenta para algumas questões relevantes sobre a fase de implantação do SINAES:

A avaliação das universidades, centros universitários e faculdades é regulada pela Lei ${ }^{\circ}$ 10.861, de 14 de abril de 2004, que instituiu o SINAES (Sistema Nacional de Avaliação da Educação Superior), sendo disciplinada pelo Decreto $n^{\circ} 5.773$, de 9 de setembro de 2006. São previstos três processos: a avaliação interna, a avaliação externa das instituições e dos cursos e a avaliação dos estudantes.

A primeira é feita pela própria instituição, por intermédio dos métodos de 
autoavaliação; a externa, pelo Ministério da Educação (quando se tratam de organizações mantidas pela União Federal ou pela livre iniciativa) que prevê critérios de verificação das condições de oferta e a última, dos alunos, por meio de aferição do desempenho acadêmico dos estudantes dos cursos de graduação, que é feita pelo ENADE (Exame Nacional de Desempenho dos Estudantes). Essa estrutura legal é perfeita e encontra cobertura tanto da Lei de Diretrizes e Bases da Educação Nacional, como da Constituição Federal. Ocorre, contudo, que o Poder Público não vem conseguindo exercer corretamente o seu dever (o de avaliar, na forma da lei) as instituições e cursos. Inicialmente, justificando falta de recursos financeiros, criou taxa para verificação in loco. O Congresso Nacional acolheu a proposta e editou lei específica, fixando valores, aliás, significativos, para que o governo cumprisse com sua obrigação.

Considerando que inexistiram questionamentos judiciais até o presente momento, as mantenedoras pagam para serem visitadas. Mesmo assim, em face das dificuldades da burocracia estatal, somada a outros fatores internos, como a carência de avaliadores capazes de verificar o funcionamento de 2.500 entidades e de mais de 26.000 cursos, o Executivo resolveu criar mecanismos simplificados, por meio de portarias ministeriais que se chocam frontalmente com a lei.

Iniciou-se a fase dos indicadores provisórios, índices de diversas categorias, conceitos preliminares e estabeleceu-se um perverso ranking das escolas superiores. Agrava-se a situação quanto não há um prévio direito dos avaliados a conhecerem seus desempenhos. Os resultados são anunciados através de bravatas governamentais nacionalistas junto à grande imprensa, estampando resultados preliminares que se tornam fatais para muitas universidades, centros e faculdades. No dia 31 de agosto de 2009, o Brasil conheceu mais um ilegal ranking cujas bases são mecanismos definidos por técnicos da máquina ministerial. Os resultados poderão ser contestados, por meio de recursos administrativos ou judiciais, mas, mesmo que esse quadro legal seja revertido, existirão consequências sociais e econômicas imprevisíveis (Informativo..., 2009, disponível online).

A tudo que foi apresentado, se soma a falta de pessoal técnico treinado e interessado em promover o processo de autoavaliação, o que tem deixado os resultados nas gavetas. Sem a utilização desses resultados e sem o envolvimento dos atores do processo, não se cria a cultura de avaliação. Certamente, as IES que a utilizarem para se aperfeiçoarem internamente terão condições de melhores projeções externas.

Deparamo-nos, em nossa reflexão, com vários aspectos da política avaliativa e, particularmente, com dois pontos de vista cruciais: a avaliação formativa e a mercadológica.

Nesse espaço de contradições, na esfera da avaliação institucional, e frente às mudanças internas e externas globalizadas, haverá condições de se consolidar um processo avaliativo que favoreça a participação dos atores institucionais como sujeitos desse processo?

Dentro desse contexto, há a possibilidade de provocarmos uma cultura de avaliação sustentada no viés formativo? 
Como pensar a relação entre ensino formador de pesquisadores, de cabeças pensantes, alunos e professores, sem os imperativos iminentes do mercado, que exigem resultados já?

Como fazer uma avaliação mais qualitativa que inclua o ator-sujeito como sujeito do desejo?

Compreendendo a universidade à luz da teoria dos quatro discursos proposta por Lacan (1992), torna-se possível analisar esta questão que se define pela relação estabelecida com o saber que opera na universidade. Para diversos autores há um processo de padronização dos atores, assim como dos processos que ocorrem na universidade, como se existisse uma só forma de agir e pensar. Isto nos remete ao conceito de sujeito e às suas posições nos discursos de Lacan, auxiliando na resposta aos enigmas relativos às instituições sociais. Alinha-se aqui o que disse Foucault (2003, p. 153): "A penalidade perpétua que atravessa todos os pontos e controla todos os instantes das instituições disciplinares compara, diferencia, hierarquiza, homogeneíza, exclui, em uma palavra, ela normatiza".

Os discursos são o novo modo de Jacques Lacan apresentar a posição dos sujeitos nos laços sociais, no centro de uma articulação inusitada entre o campo da linguagem e o campo do gozo. Para representá-los, Lacan (1992) utiliza matemas que são a formalização da lógica matemática a serviço do processo analítico. Visam permitir a transmissão de um mínimo daquilo que se decanta da experiência analítica, já que o real só pode se inscrever por uma formalização, dado sua impossibilidade de subjetivação.

Os matemas ocupam um lugar de intercessão entre fantasia e real. Os quatro discursos, do mestre, do universitário, da histérica e do analista, além do discurso capitalista, são quatro configurações significantes - embora nem tudo seja significante na estrutura do discurso - que se diferenciam e se especificam por sua distribuição espacial. Está em jogo aquilo que ordena e regula os vínculos sociais entre os sujeitos.

\section{Os Discursos em Lacan}

Como dissemos anteriormente, Lacan em suas teorias sobre os discursos desenvolve as ideias de Freud sobre a cultura e seu funcionamento. Desenvolve a ideia de que o laço social, isto é, o relacionamento entre os seres humanos, é sustentado pelos discursos, a saber: do mestre, do universitário, da histérica e do analista. Portanto, assume as características da época e da cultura em que está inserido, distinguindo-se através das formas de gozo dos sujeitos, sobre os quais exercem seus efeitos. Lacan propõe os discursos afirmando que são formas de utilização da linguagem como vínculo social, pois é na estrutura significante que o discurso se estabelece. São as articulações das cadeias significantes que geram os discursos. 
Os discursos nada mais são do que a articulação significante, o aparelho, cuja mera presença, o status existente, domina e governa tudo o que eventualmente pode surgir de palavras. São discursos sem palavras, que vêm em seguida alojar-se nele (Lacan, 1992, p. 158).

Para Lacan o discurso excede à palavra, vai mais além dos enunciados que realmente se pronunciam. $\mathrm{O}$ discurso subsiste sem palavras, porque se trata de relações fundamentais que se sustentam da linguagem. "O discurso sustenta a realidade, a modela sem supor o consenso por parte do sujeito" (Lacan, 1977, p. 21).

$\mathrm{Na}$ verdade, os discursos são para Lacan, as quatro possibilidades de relacionamento: governar, educar, analisar e fazer desejar, pensadas a partir das formulações freudianas sobre o mal-estar na civilização. A formalização dos discursos respeita uma distribuição espacial que se dá em dois níveis: quanto aos lugares - que são permanentes, e quanto aos termos:

$$
\frac{\text { agente }}{\text { verdade }} \rightarrow \frac{\text { outro }}{\text { produção }}
$$

$O$ agente: Estrutura a produção discursiva, domina o laço social, ao dar o tom ao discurso e ao possibilitar que haja alteridade. $\mathrm{O}$ agente não é aquele que age, é o agenciador, promove o discurso. É movido pela verdade, lugar que pode ser ocupado por qualquer termo. O outro: É aquele a quem o discurso se dirige. $\mathrm{O}$ outro precisa do agente para se constituir. $A$ verdade: A verdade sustenta o discurso, mas é acessível apenas pelo semidito. Ela não pode ser toda dita, havendo uma interdição entre a produção e a verdade. A produção: É o efeito do discurso, é aquilo que resta.

Há quatro termos que circulam nos lugares acima descritos: S1, a, S2, \$.

O Sl é o significante mestre - representa o sujeito como determinado pela ação significante. É a condição da articulação da cadeia, estando, de alguma forma, fora dela. É um significante vazio de significação. Ele comemora a erupção de um gozo associado ao $S 2$ (saber), inicia uma linguagem.

O $S 2$ é o matema do saber - significante diante do qual S1 representa o sujeito - ligação em que se estrutura a cadeia mínima para a significação.

Objeto a - causa de desejo ou mais-de-gozar. Lacan verificou que a estrutura do inconsciente estava incompleta e distante do desejado. Para Lacan, o sujeito nunca é completo a partir do seu próprio eu. A função do objeto a é de simbolizar a falta do Outro, é um gozo que escapa.

Sujeito Barrado \$ é o sujeito marcado pela barra - a possibilidade de vir a ser. O sujeito é, para Lacan, esvaziado de toda substância.

No momento em que o significante (S1) intervém no campo do Outro (A), campo estruturado por um saber (S2) em que outros significantes se articulam, surge o sujeito dividido (\$). Nesse caminho há também uma perda, que Lacan denomina objeto a. Esta estrutura é chamada por Lacan (1992) de Discurso do Mestre: 


$$
\frac{\mathrm{S} 1}{\$} \rightarrow \frac{\mathrm{S} 2}{\mathrm{a}}
$$

Partindo do Discurso do Mestre, surgem três estruturas discursivas, levando em conta que a cadeia simbólica não pode ser desarrumada - com exceção do Discurso do Capitalista, abordado mais adiante. Cada uma das estruturas desses discursos é diferente da outra pela posição dos termos. Lacan chama seus discursos de pequenos quadrípodes giratórios, definindo quatro discursos radicais.

Esses discursos segundo Lacan (1992) dão sustentação ao mundo, fazem parte de seus pilares. A cada um quarto de giro dos termos pelas posições, obtemos cada um dos quatro discursos, que se seguem:

\begin{tabular}{|cc|}
\hline Discurso do Mestre & Discurso Universitário \\
$\frac{\mathrm{S} 1}{\$} \rightarrow \frac{\mathrm{S} 2}{\mathrm{a}}$ & $\frac{\mathrm{S} 2}{\mathrm{~S} 1} \rightarrow \frac{\mathrm{a}}{\$}$ \\
Discurso da Histérica & Discurso do Analista \\
$\frac{\$}{\mathrm{a}} \rightarrow \frac{\mathrm{S} 1}{\mathrm{~S} 2}$ & $\frac{\mathrm{a}}{\mathrm{S} 2} \rightarrow \frac{\$}{\mathrm{~S} 1}$ \\
\hline
\end{tabular}

Além dos quatro discursos há, ainda, o Discurso do Capitalista, fora da ordem lógica dos discursos:

$$
\frac{\$}{\mathrm{~S} 1} \rightarrow \frac{\mathrm{S} 2}{\mathrm{a}}
$$

O Discurso do Capitalista, ao qual Lacan se refere no Seminário 17, não é propriamente um outro discurso, mas uma forma mais contemporânea de pensar o discurso do mestre (Quinet, 2006). Cabe verificar que as posições mudaram e apenas o lugar da verdade permanece o mesmo. Mas não existe nenhuma relação entre o agente e o outro: não há laço social no discurso do capitalista, não há vínculo entre o capitalista e o proletário.

Com a alternância dos termos nos quatro lugares, obtemos os diferentes discursos:

Discurso do Mestre:

$$
\frac{\mathrm{S} 1}{\mathrm{~S}} \rightarrow \frac{\mathrm{S} 2}{\mathrm{a}} \frac{\text { senhor }}{\text { sujeito barrado }} \rightarrow \frac{\text { escravo }}{\text { gozo }}
$$

A verdade do mestre é a castração. $O$ escravo tem algum saber sobre a castração do senhor, pois o \$ no lugar da verdade indica que o sujeito é dividido. 
Discurso Universitário:

$$
\frac{\mathrm{S} 2}{\mathrm{~S} 1} \rightarrow / / \frac{\mathrm{a}}{\mathrm{S}} \underset{\text { significante mestre }}{\text { professor }} \rightarrow \frac{\text { a-estudante }}{\text { sujeito dividido e alienado }}
$$

Aqui, o saber ocupa a posição dominante; o sujeito sapiente é o agente. $\mathrm{O}$ professor transmitirá o ensino. $\mathrm{O} a$, como outro, representa o estudante - ou $a$ estudante, como prefere Lacan (1992) - que, causado pelo desejo, realiza o trabalho de escrever, sendo explorado pelo discurso universitário.

O produto da universidade é um sujeito barrado - (\$), incompleto, que sempre terá desejo de saber mais. Lacan diz que o estudante entra na universidade, achando que sabe tudo e sai consciente de que não sabe nada. O S1 aparece no lugar da verdade, que ordena: “- Vai, continua. Não para! Continue... a saber, sempre mais" (Lacan, 1992, p. 98).

Este discurso tem no educador o seu principal agente, ao mesmo tempo sujeito e assujeitado. Assujeitado, sim, porque o professor não ensina os conteúdos que ele produz, mas sim peça da engrenagem da instituição que o autoriza ou não a ser livre para pensar e agir. Portanto, esse professor não se autoriza por si próprio, mas sim através de Outros.

Discurso da Histérica:

$$
\frac{\$}{\mathrm{a}} \rightarrow \frac{\mathrm{S} 1}{\mathrm{~S} 2} \frac{\text { sintoma }}{\text { causa de desejo }} \rightarrow \frac{\text { mestre }}{\text { saber }}
$$

O discurso da histérica tem grande importância para a psicanálise. Foi na escuta desse discurso que Freud fundou a psicanálise e sua descoberta principal, o inconsciente. O S2 aparece, portanto, na posição de produção.

Discurso do Analista:

$$
\frac{\mathrm{a}}{\mathrm{S} 2} \rightarrow \frac{\$}{\mathrm{~S} 1} \frac{\text { desejo inconsciente }}{\text { enigma }} \rightarrow \frac{\text { sujeito dividido }}{\text { significante mestre }}
$$

Neste discurso não vigora o imperativo de dominar e amestrar. O discurso do analista é uma maneira de tratar do mal-estar considerando o outro como sujeito. Constitui uma saída do discurso capitalista. A experiência analítica é, para Lacan, uma experiência de discurso, uma experiência da ordem do saber, que liga S1 a S2.

O discurso universitário parece ter predomínio no âmbito da universidade, tanto no ambiente burocrático, quanto no ambiente acadêmico, evidenciandose isto nas formas quantitativas da avaliação. Mas a experiência discursiva universitária não deveria resumir-se ao discurso universitário.

Seria isto possível sem uma participação, efetiva, fundamentada em um desejo real de participação dos atores-sujeitos? Seria isto possível sem o giro no discurso da burocracia? 
A nosso ver, em consequência desta predominância do discurso universitário, o exercício da avaliação institucional nos espaços institucionais vem mostrando, pelas situações vivenciadas, um distanciamento entre estes mesmos processos de avaliação desencadeados e as práticas dos sujeitos, com desencontros e lógicas discordantes que impedem, devido ao seu potencial de exclusão dos sujeitos, como comentado anteriormente, o alcance das mudanças almejadas pela avaliação. Os discursos podem girar por posições distintas, assumidas por docentes e alunos frente à construção e transmissão do saber. Ou seja, girar para a posição histérica, pois conforme Lacan (1992), a posição histérica é o avesso da padronização da burocracia, porque é lugar de produção do saber novo.

A inclusão desta posição discursiva tem como efeitos saudáveis confrontos e convergências de ideologias e representações. Essas tramas institucionais interferem no processo avaliativo de forma positiva ou não, mas são sempre lugares que propiciam o novo.

Esta questão impõe-nos pensar nas posições discursivas ocupadas na universidade e seus efeitos na avaliação, tendo em vista, estabelecer uma relação entre as posições discursivas e as avaliações regulatória e formativa.

Sabemos que todos os discursos (mestre, analista, capitalista, universitário e da histérica), podem circular no ambiente universitário. No entanto, as estruturas discursivas predominantes no discurso universitário têm como consequência a exclusão do sujeito do desejo e a consequente inércia do atorsujeito quanto a uma participação efetiva tanto nos processos de avaliação quanto na execução do que decorre dela. A abertura ao discurso da histérica, como se disse, pode ser a via, no âmbito da universidade, da inclusão do sujeito do desejo. Assim, temos a intenção de analisar as possíveis contribuições que o giro nas posições discursivas, particularmente, para a posição histérica, pode oferecer para um melhor desempenho do processo de avaliação institucional no ambiente universitário.

Esta adoção do discurso histérico refere-se ao afloramento do sujeito que anseia saber acerca de sua falta, a partir de seus erros, lugar no qual S2 (o saber) é incapaz de dar conta de sua divisão. Assumir a posição do discurso histérico possibilita ao ator-sujeito encontrar-se com o que é um fato da estrutura. É como sujeito barrado que ele pode permitir a articulação e o deslizamento significante e impedir a sua estagnação. $O$ discurso histérico surge por meio do desejo, no ato de dizer, na busca particular do que falta ao próprio saber que se transmite. A construção de saber é ordenada pelo que não se sabe, mas interroga.

A circularidade dos discursos no âmbito universitário faz-se fundamental para a evolução das relações com o saber na universidade, tendo como premissa que o discurso da histérica proporciona interrogações ao saber estático.

É esta alienação que nos permite concluir que os processos avaliativos estão inseridos no discurso universitário, da burocracia, padronizado, cuja Produção é o sujeito alienado e conforme Lima, silenciado pelos 
[...] cânones construídos históricos e culturalmente: pode-se dizer, não se pode dizer, é proibido, não é proibido, pode-se fazer, não se pode fazer. Quando existe falta de liberdade para se agir nos espaços públicos, age-se com a liberdade do silêncio[...] os significados do silêncio podem ser uma manifestação de resistência ao processo de condução da avaliação (Lima, 2002, p. 143).

Isto não explicaria a falta de adesão, aos processos de avaliação?

Para buscar uma saída desta alienação não seria desejável o giro para o discurso da histérica? Giro que permitiria a instalação de formas coletivas de condução e resolução das dificuldades que dessem sentido à construção de intercâmbios novos, superadores dos burocraticamente estabelecidos, com a participação dos atores envolvidos nas práticas de avaliação?

$\mathrm{Na}$ avaliação institucional, exclusivamente quantitativa, em nome de uma objetividade científica, usa-se uma contabilidade que tenta definir antecipadamente o bom do ruim. Essa prática inibe o sujeito de fazer suas escolhas autênticas, pois, o sujeito que emerge é o da objetividade, o que é verdade no sujeito fica submerso. Elia diz:

A psicanálise é proveniente da ciência, contudo não se reduz a ela, não se estabelece no campo da ciência porque a noção de sujeito é a sua chave fundamental. Ela toma para si o peso da verdade, assumindo a responsabilidade por ela, seja qual for a sua natureza. A psicanálise recoloca o sujeito na cena discursiva, fato que a ciência, para se fundar, necessariamente excluiu (Elia, 2000, p. 20)

Com a posição mais próxima do discurso da histeria, o discurso universitário talvez pudesse tornar-se menos unívoco e totalitário, apontando-se o impossivel de se avaliar. Possibilitar o giro do discurso universitário para o discurso da histérica, pelo desejo de trocar experiências com seus pares, faria o processo avaliativo mais dinâmico. Assim como governar, ensinar e analisar são profissões impossíveis (Freud, 1975, p. 282), é igualmente impossível avaliar. Esta impossibilidade, entretanto, torna a avaliação ainda mais necessária.

\section{Considerações Finais}

Por ser uma prática encarada como um processo, a avaliação institucional, deve ser capaz de provocar novos debates na comunidade acadêmica, colaborando na revisão dos comportamentos e na reestruturação das práticas administrativas pelo estímulo à interação e ao diálogo entre os atores para melhor conhecimento da instituição, como um lugar de construção para um ensino melhor.

As ações coletivas e dinâmicas devem ser incentivadas para que haja sinergia entre os envolvidos, o que dará a eles autoridade quanto à expressão de suas vivências individuais e melhor qualidade na avaliação. Também a 
capacitação dos avaliadores tem se mostrado escassa e inconsistente, mas fundamental para a condução do processo.

De acordo com Ristoff e outros autores, o PAIUB (Programa de Avaliação Institucional das Universidades Brasileiras) foi o Programa de Avaliação que mais chegou perto do ideal em avaliação por seu potencial transformador. Para Ristoff (2000, p. 40-50) “[...] o PAIUB se baseou nos seguintes princípios: o da globalidade, comparabilidade, respeito à identidade institucional, não premiação ou punição, adesão voluntária, legitimidade e continuidade". Sendo o PAIUB um momento único na história da avaliação, disse Ristoff:

A verdade é que, durante os anos de 1993 e 1994, o país viveu um momento realmente histórico no tocante à avaliação. As iniciativas da Associação Nacional de Dirigentes das Instituições Federais de Ensino Superior (ANDIFES), da Associação Brasileira dos Reitores das Universidades Estaduais e Municipais (ABRUEM), dos Fóruns de Pró-Reitores de Graduação e Planejamento encontraram eco na equipe, ideologicamente plural do MEC. Este passou a exercer o papel não condutor do processo, mas de articulador, de viabilizador e, por fim, de financiador. E isto talvez esteja fazendo toda a diferença (Ristoff, 2000, p. 38).

Na linguagem de psicanálise podemos dizer que foi uma avaliação que se fez sobre laços sociais e levou em conta o desejo dos sujeitos. Conseguiu adesão espontânea, foi discutida em caráter nacional e respeitou a autonomia das instituições, provocando debates nacionais. Mas a política produziu um giro para o discurso capitalista, com a entrada no cenário nacional do ENC (Exame Nacional de Cursos), totalmente quantitativo, obrigatório e regulador, de acordo com Dias Sobrinho (2003) a serviço dos interesses das forças de mercado.

O PAIUB segundo Dias Sobrinho:

[...] Este programa resultou de um amplo acordo com as instituições de educação superior, de todas as naturezas jurídicas ou administrativas e de todos os quadrantes do país, com as autoridades do Ministério da Educação, no ano de 1993. Pode ser considerado um modelo ou enfoque de avaliação, pois comporta, de forma consistente e coerente, concepções, princípios e metodologias de avaliação (Dias Sobrinho, 2003, p. 82).

Já o SINAES foi concebido para resgatar a cultura de avaliação dispersa construída pelo PAIUB e a criação de um programa que possibilitasse a integração dos vários mecanismos de aferição. É a tentativa de organizar uma avaliação de caráter continuado. Há discordâncias quanto o processo e seus efeitos.

Nas Diretrizes do SINAES/CONAES não se utiliza a expressão avaliação com fins regulatórios ou avaliação regulatória.

$\mathrm{Na}$ avaliação, as instituições passam a comparar o projeto da IES, e a sua realidade institucional e a melhorar a qualidade acadêmica. No contexto de cada IES constrói-se uma proposta de autoavaliação voltada para a globalidade da 
instituição, buscando dimensionar a relação entre o projeto institucional e sua prática, para reformulá-lo no planejamento e nas ações futuras da instituição. Elabora-se uma metodologia que organiza as atividades dos diferentes atores envolvidos no processo avaliativo, buscando a construção de um sistema integrado. Deste modo, ampliam-se as formas de compreensão sobre a instituição, visando aperfeiçoar os diferentes setores.

Busca-se conciliar a ideia da avaliação emancipatória com a regulação, dividindo o processo em três momentos: o primeiro realizado pelo poder público "precede o processo de avaliação nas etapas iniciais da autorização e do credenciamento dos cursos"; o segundo é o processo da avaliação propriamente dita, "que se realiza autonomamente pela instituição de forma integrada e segundo suas diferentes modalidades"; o terceiro, após o parecer da CONAES (Comissão Nacional de Avaliação) pelo Poder Público "são aplicados os efeitos regulatórios - previstos em lei - decorrentes da avaliação" (Brasil/CONAES, 2004, p. 10).

Mas que tipo de avaliação nos interessa? Em qual delas a adesão poderia melhorar?

As instituições não podem fugir das normas estabelecidas pela Política Nacional de Ensino, mas em sua política interna, podem exercer uma avaliação que contemple a participação desejante dos atores-sujeitos, permitindo ações que minimizem o mal-estar, que levem ao resultado desejado, a uma cultura de avaliação. Chamamos a atenção para o significado da palavra ator que nos aponta para a presença do sujeito do desejo, uma vez que ator é aquele que pratica o ato. Para a psicanálise, ato implica em transformação, criação, espanto, surpresa, efeitos da presentificação do desejo. Portanto, atores-sujeitos, é uma expressão que marca duplamente a presença do desejo, seja pelo termo ator, seja pela concepção de sujeito.

A questão da resistência na participação dos funcionários, professores e alunos, ou seja, dos atores-sujeitos, ao processo e à implantação da cultura de avaliação é reveladora de um mal-estar. A criação de uma cultura de avaliação institucional deve ser considerada como um processo educativo. A cultura é expressa na universalidade, na singularidade e na particularidade da instituição e de seus atores.

Entendemos que a contribuição da psicanálise para com este trabalho se faz, sobretudo, com suas concepções sobre as relações entre sujeito e desejo. Parece-nos imprescindível que o ator institucional saia da margem da avaliação constituindo-se realmente como ator-sujeito neste processo para se viabilizar a implantação da cultura de avaliação. Porém existe uma grande lacuna entre as práticas de avaliação e a implantação desta. Acreditamos que esse espaço não ocupado seja o do desejo dos atores-sujeito.

A adoção de uma concepção formativa da avaliação faz toda a diferença para o sucesso da mesma na instituição de ensino, ensejando novas possibilidades para desenvolver um processo avaliativo mais saudável, mais democrático e mais prazeroso. 
Pensamos no discurso da histérica como avesso da dominação, pelo seu questionamento ao saber estabelecido, ou seja, pelo abandono da concepção do saber como verdade. Nesse caso, poderemos ter o privilégio de articular saber e desejo no ambiente universitário.

Em seu livro Psicose e Laço Social, Antonio Quinet (2006, p. 37), faz a seguinte observação à histerização do discurso universitário:

A histeria, como avesso do discurso universitário da burocracia, faz objeção ao totalitarismo perverso do saber, seja ele qual for. Esse discurso é o responsável pela utilização do saber como forma de tratamento do mal-estar na civilização. A histeria como produção de saber provocado pelo sujeito é o que faz Lacan encontrar a afinidade da ciência com o discurso da histérica - que é o melhor que se pode esperar da ciência. O pior é quando ela se encontra a serviço do discurso do capitalista (nova modalidade do discurso do mestre) [...]. O sujeito histerizado pelo discurso universitário restitui, em seu laço social, um mestre que produzirá o saber que promove, ao ser agente, o discurso universitário. E assim por diante- o que não constiui propriamente uma saída (grifo nosso).

Mas, quando se está capturado por um discurso autoritário, cala-se o sujeito, este fica assujeitado. Mesmo assim, os sujeitos são sempre dotados de alguma liberdade e iniciativa. Nunca se submetem por completo à autoridade e sempre tem uma iniciativa que o detentor da autoridade não havia previsto, portanto, não há como padronizar. Isto significa que não há como deter inteiramente o sujeito.

Recebido em outubro de 2010 e aprovado em setembro de 2011.

\section{Referências}

BELLONI, Isaura. A Função Social da Avaliação Institucional. Avaliação: revista da Rede de Avaliação Institucional do Ensino Superior, Campinas, v. 3, n. 3, p. não informada, 1998

BOCLIN, Roberto. Avaliação Institucional: quem acredita? Rio de Janeiro: Espaço do Saber, 2006.

BOURDIEU, Pierre. Os Usos Sociais da Ciência: por uma sociologia clínica do campo científico. São Paulo: Fundação Editora da UNESP, 2003.

BRASIL. Constituição (1988). 2. ed. São Paulo: Saraiva, 1999.

BRASIL. Lei n ${ }^{0} 5.540 / 68$, de 28 de novembro de 1968. Fixa Normas de Organização e Funcionamento do Ensino Superior e sua Articulação com a Escola Média, e dá Outras Providências. Diário Oficial [da] República Federativa do Brasil, Brasília, DF, 29 de abr. 1968. Disponível em: <http://www.planalto.gov.br/ccivil_03/Leis/L5540.htm>. Acesso em: 2 jul. 2010.

BRASIL. Lei no 9.394, de 20 de dezembro de 1996. Estabelece as Diretrizes e Bases 
da Educação Nacional. Diário Oficial [da] República Federativa do Brasil, Brasília, DF, 23 dez. 1996. Disponível em: <http://www.planalto.gov.br/ccivil_03/Leis/L9394. htm>. Acesso em: 2 jul. 2010.

BRASIL. Lei n ${ }^{\circ} 10.861$, de 14 de abril de 2004. Institui o Sistema Nacional de Avaliação da Educação Superior - SINAES e dá outras providências. Diário Oficial [da] República Federativa do Brasil, Brasília, DF, 15 abr. 2004. Disponível em: <http://www. planalto.gov.br/ccivil_03/_ato2004-2006/2004/lei/110.861.htm>. Acesso em:_2 jul. 2010. BRASIL. Ministério da Educação e Cultura. Diretrizes para a Avaliação das Instituições de Educação Superior. Brasília: CONAES, 2004.

BRASIL. Ministérios da Educação e Cultura. Plano Nacional de Educação. Brasília: INEP, 1998.

BRASIL. Ministério da Educação e Cultura. Políticas e Resultados, 1995-2002: ensino superior maior e melhor. Brasília, DF: MEC, 2002.

CARNEIRO, Breno Pádua Brandão; NOVAES, Ivan Luiz. Avaliação: as comissões próprias de avaliação frente ao processo de regulação do ensino superior privado. Revista da Avaliação do Ensino Superior, Campinas, v. 13, n. 3, p. 713-732, nov. 2008. CUNHA, Luiz Antônio. Desenvolvimento Desigual e Combinado no Ensino Superior: estado e mercado. Educação e Sociedade, Campinas, v. 25, n. 88, p. 795-817, out. 2004.

DIAS SOBRINHO, José. Avaliação: políticas educacionais e reformas da educação superior. São Paulo: Cortez, 2003.

ELIA, Luciano. Psicanálise: clínica \& pesquisa. In: ELIA, Luciano. Clínica e Pesquisa em Psicanálise. Rio de Janeiro: Rios Ambiciosos, 2000. P. 19-35.

FOUCAULT, Michel. Microfísica do Poder. Rio de Janeiro: Graal, 2003.

FREUD, Sigmund. Análise Terminável e Interminável (1937). In: FREUD, Sigmund. Obras Completas de Sigmund Freud, v. 23. Edição Standard Brasileira. Rio de Janeiro: Imago Editora, 1975.

FREUD, Sigmund. O Mal-Estar na Civilização (1930). In: FREUD, Sigmund. Obras Completas de Sigmund Freud, v. 21. Edição Standard Brasileira. Rio de Janeiro: Imago, 1975.

FREUD, Sigmund. Psicologia das Massas e a Análise do Eu (1921). In: FREUD, Sigmund. Obras Completas de Sigmund Freud, v.18. Edição Standard Brasileira. Rio de Janeiro: Imago, 1975.

INFORMATIVO do Ensino Superior. Rio de Janeiro: IPAE, ano 20, n. 234, ago. 2009. Disponível em: <http://www.ipae.com.br/pub/pt/jee/3585/index.htm>. Acesso em: 2 jul. 2010.

LACAN, Jacques. A Ciência e a Verdade. In: LACAN, Jacques. Escritos. Rio de Janeiro: Jorge Zahar, 1998.

LACAN, Jacques. O Seminário, livro 11: os quatro conceitos fundamentais da Psicanálise. Rio de Janeiro: Jorge Zahar, 1979.

LACAN, Jacques. O Seminário, livro 17: o avesso da psicanálise. Rio de Janeiro: Jorge Zahar, 1992.

LIMA, Elizeth Gonzaga dos Santos. Avaliação Institucional: a experiência da UNEMAT - entrelaçando as vozes e tecendo os fios do silêncio. Porto Alegre: UFRGS, 2002. PERRENOUD, Philippe. Avaliação: da excelência à regulação das aprendizagens. 
Porto Alegre: Artmed, 1999.

QUINET, Antonio. Psicose e Laço Social. Rio de Janeiro: Jorge Zahar, 2006.

RISTOFF, Dilvo Ilvo; DIAS SOBRINHO, José (Org.). Universidade Desconstruída: avaliação institucional e resistência. Florianópolis: Editora Insular, 2000.

SILVA, Tadeu Tomaz da. Neoliberalismo, Qualidade Total e Educação: visões críticas. Petrópolis: Vozes, 2007.

SINAES. Sistema Nacional de Avaliação da Educação Superior: da concepção à regulamentação. 2 ed. ampliada. Brasília: Instituto Nacional de Estudos e Pesquisas Anísio Teixeira, 2004.

UNESCO. Declaração Mundial sobre Educação Superior no Século XXI: visão e ação. In: CONFERÊNCIA MUNDIAL SOBRE ENSINO SUPERIOR, 1998, Paris. Anais... Disponível em: $<$ http://www.interlegis.leg.br/processo_legislativo/copy_of_20020319 150524/20030620161930/20030623111830/>. Acesso em: 3 jul. 2010.

Eliane Gomes dos Santos é graduada em Comunicação Social pela PUC/RJ. Especialista em Documentos Oficiais e Pesquisa em Comunicação. Mestre pelo Mestrado em Psicanálise, Saúde e Sociedade da Universidade Veiga de Almeida. Avaliadora e Membro da Comissão Própria de Avaliação da Universidade Veiga de Almeida, Rio de Janeiro, RJ - CPA/UVA.

E-mail: egomes@uva.br

Maria da Glória Schwab Sadala é psicanalista, Doutora pela UFRJ. Coordenadora do Curso de Mestrado em Psicanálise, Saúde e Sociedade e do Curso de Especialização em Teoria Psicanalítica e Prática Clínico-Institucional da Universidade Veiga de Almeida, Rio de Janeiro, RJ. Supervisora do SPA/UVA. Professora e Supervisora do Curso de Especialização em Psicologia Clínica da PUC/RJ. Membro do Colegiado de FCCL-RJ.

E-mail: gloriasadala@uva.br

Sônia Xavier de Almeida Borges é psicanalista da Escola de Psicanálise do Campo Lacaniano. Graduada em Pedagogia pela PUC/Goiás. Especialista em Psicologia da Educação pela UFG. Mestre em Psicologia da Educação pela FGV/RJ. Doutora em Psicologia da Educação pela PUC/SP. Professora da Universidade Veiga de Almeida, Rio de Janeiro, RJ, nos Cursos de Graduação em Psicologia, Pós-graduação em Teoria Psicanalítica e Prática ClínicoInstitucional e do Mestrado em Psicanálise, Saúde e Sociedade.

E-mail: sxborges@uol.com.br 